\title{
Biomass valorization for better aviation environmental impact through biocomposites and aviation biofuel
}

\begin{abstract}
The expansion of international civil aviation over the past two decades has been significant. Air traffic is accounted by Revenue Passenger Kilometre (RPK), and this has historically doubled every 15 years. The forecast for the next 20 years is between a 4.3 to $4.8 \%$ increase in air traffic per year, with the main driver being Asia Pacific in terms of growth percentage. Current global civil aviation accounts for approximately $2 \%$ of man-made carbon dioxide (CO2) emissions. ICAO (International Civil Aviation Organization), under the United Nations, to have the aviation industry to pledge reduction in its emissions through its four pillars of innovation, which are: (i) Product Technology, (ii) Operations and Infrastructure, (iii) Economic Measures, and (iv) Sustainable Fuel. It is expected that Technology and Biofuels are the two largest contributors to meet the carbon dioxide reduction goals. The utilization of biojet fuel and bio-composite contributes to the aviation industry's reduction in $\mathrm{CO} 2$ and improving the sustainability of the industry. Bio-jet fuel development are maturing with up to 5 certified pathways, all which yields synthetic fuel with improved fuel performance, lowered soot formation and $\mathrm{CO} 2$ emission. Bio-composites improves the sustainability factor of a plane, rather than composite fibers derived from non-renewable sources. Bio-composites has a long development road map, and the usage of renewable, sustainable sources is key for implementation onto an aircraft. Biomass valorization is needed for a better aviation environmental footprint, however the cost factor is still high. However, with limited fossil fuels, the cost of fossil fuel-derived products will increase with diminishing of the source. The key to enable the aviation industry to adopt biomass derived products is for the biomass to be sustainable and renewable. Sustainability of the feed-stock and its abundance is needed to support a growing aviation industry, and to ensure the safety standards that the industry is known for.
\end{abstract}

Keyword: Biocomposites; Biofuel; Emissions; Jet fuel; Renewables; Sustainable 